\title{
Interactive Dynamic Assessment, A Diagnostic Tool for Children with Fetal Alcohol Spectrum Disorder
}

\section{Linda Wason-Ellam}

\author{
Department of Curriculum Studies, University of Saskatchewan, Saskatoon, SK, Canada
}

There is a sizable volume of research on how children learn to read and write on their educational journey. Unfortunately, the development of these skills and assessments that are predecessors to conventional reading and writing abilities for learners are absent for readers with Fetal Alcohol Spectrum Disorder (FASD). Due to the range of effects that can occur in an individual whose mother consumed alcohol during pregnancy children with a diagnosis of FASD often lack the implicit processes and tacit knowledge that underpins reading, writing, and communicative skills. Children diagnosed with FASD, a spectrum of conditions caused by prenatal alcohol exposure, struggle academically in school [1]. The damage manifests in a range of difficulties with adaptive behaviour, attention, cognition, executive functioning and memory. As a result, individuals with FASD may have trouble with abstract reasoning, organization, planning, understanding or recalling a sequence of events, connecting cause and effect relationships, due to the impulsivity, frustration and/ or regulating their own behaviours and emotions. Their disability often leads to lower reading, writing, and oral and social skills, in addition to a loss of self-esteem. In most cases, many have reduced school completion rates, and disruptive emotional behaviours resulting in behavioral program placements.

Subsequently, literacy skills for these learners are generally absent from the literature especially on reading and writing [2]. Reading, writing and communicative interventions are key to providing children with an opportunity to succeed at school and throughout their life span. In providing appropriate educational experiences for these students, there is a need that exists for research on the patterns of reading, writing, and communicative profiles so that a range of individualized interventions can be tailored for children with FASD [3].

The focus of this longitudinal study of struggling readers and writers with an existing diagnosis of FASD often lack the implicit processes and tacit knowledge that underpins reading. Thus, objectives of this qualitative study were to (1) Design a dynamic assessment model applied during learning, which identifies specific cognitive problems underlying language, reading and visual skills for readers (2) To identify interactive multi-modal strategies as in drawing, photography, digital images, concept mapping, talk-drawwrite-tell-stories or story boards and storytelling with graduated prompts that are developmentally appropriate and brain compatible. To focus learners' attention, maximize working memory, and foster meaningful connections with prior schema, and visualizing, which enhance connections in neural networks.

Participants: There were no cohorts of struggling readers with FASD within any one school; therefore, the participating students were recruited in several schools within the range of the city and the surrounding outskirts. There were 46 participants, (19 girls and 26 boys) in grades 2 to 6 , and 6 teenage boys in a variety of Grades 10 to 16 levels who had an on-going literacy struggle throughout the elementary grades and became participants in the longitudinal study over a ten-year period, Three of the students graduated from a university or a technical school.

\section{Publication History:}

Received: December 05, 2019

Accepted: January 02, 2020

Published: January 04, 2020

\section{Keywords:}

\section{FASD, Alcohol, Diagnostic tool, Visualization}

Research Methodology: The purpose of this qualitative research was to use ethnography, a naturalistic inquiry (studying interventions for readers and writers in an everyday environment) and by observing and listening to how a child learned. All the children diagnosed with FASD experienced difficulty with integrating components of comprehension during reading and had trouble in writing. (1) Participant observation was used to view these readers and writers who struggled to meet grade level expectations especially in reading as schools participated in differentiating students and questioning their underachievement rather than question how practices can be adapted to meet the learners' needs. Reading comprehension depends upon field text techniques used for documenting in-school literacy interventions which are diagnostic tools applied during reading, drawing or writing tasks. Having a solid foundation in oral language and a large vocabulary will help children become successful readers and strong communicators as well as build their confidence and overall sense of well-being. Proficient readers have a large vocabulary and a wide-range experience. They are aware of why they are reading a text, as the gain an overview of the text before reading to stimulate prior knowledge, make predictions about the upcoming text, read selectively based on their overview, associate ideas in text to what they already know, note whether their predictions and expectations about text content are being making sense. If not, they revise their prior knowledge when compelling new ideas conflicting with prior knowledge are encountered, figure out the meanings of the text. While less-skilled readers are often bogged down in the reading process and are placed in resource rooms working on a workbook curriculum and misses the social connections that are paramount in the classroom [4]. (2) Field notes were collected from general observations which are the written account of what the researcher sees, hears, experiences, and thinks in the course of collecting and reflecting on reading and writing skills and how the child responds were collected over seven to ten-years. (3) Teacher interviews on the formative progress of their students about reading were conferenced. One of which was word recognition and the other was reading comprehension throughout the reading process and learning about dynamic assessment as a measure using rubrics rather than using grade levels.

"Corresponding Author: Dr. Linda Wason-Ellam, Department of Curriculum Studies, University of Saskatchewan, Saskatoon, SK, Canada; E-mail: linda.wason-ellam@usask.ca

Citation: Wason-Ellam L (2020) Interactive Dynamic Assessment, A Diagnostic Tool for Children with FASD. Int J Pediatr Neonat Care 6: 161. doi: https://doi. org/10.15344/2455-2364/2020/161

Copyright: (C) 2020 Wason-Ellam. This is an open-access article distributed under the terms of the Creative Commons Attribution License, which permits unrestricted use, distribution, and reproduction in any medium, provided the original author and source are credited. 
Pedagogy: Reading is a complex activity. The goal was to present dynamic assessment as a diagnostic tool that measures thinking, visualizing, predicting, meaning making, and problem solving as an active teaching tool aimed at modifying cognitive functioning for struggling readers with FASD [5]. Visual Images are a monitor of comprehension. When students with a FASD diagnosis are taught to generate mental images while reading, their recall increases and so does their ability to predict a text and makes inferences about what that are reading. Using Talk-Drawings are an illustration of what the texted stated makes the meaning of the words more memorable.

Interactive Dynamic Assessment (DA) is a diagnostic tool that refers to an assessment, by an active teaching process, of a child's perception, learning, thinking, and problem solving. The process is aimed at modifying an individual's cognitive functioning and observing subsequent changes in learning and problem-solving patterns within the testing situation [6] The goals of the DA are to: (1) assess the capacity of the child to grasp the principle underlying an initial problem and to solve it, (2) assess the nature and amount of investment (teaching) that is required to teach a child a given rule or principle, and (3) identify the specific deficient cognitive functions (i.e., systematic exploratory behavior) and non-intellective factors (i.e., need for mastery) that are responsible for failure in performance and how modifiable they are as a result of teaching.

Visual Images are a monitor of comprehension. When students with a FASD diagnosis are taught to generate mental images while reading, their recall increases and so does their ability to predict a text and makes inferences about what that are reading. Using Talk-Drawings are an illustration of what the texted stated and makes the meaning of the words more memorable. Readers with FASD can read words but often have difficulty developing and understanding a sense of story structure [7]. Reading is a complex problem-solving process involving perception, language and thought. It consists of two related intentional processes, word recognition, which is perceiving how written symbols correspond to spoken language and comprehension, which is constructing meaning [8]. Both processes operate continuously and simultaneously, integrating the reader's perceptions over the story, while bridging newly constructed knowledge networks to the reader's schema of background experiences and linguistic patterns [9]. Struggling readers with FASD need to encounter executive functioning difficulties incomprehension, predicting, summarizing, sequencing, inferring, questioning, figuring outwords and connecting background knowledge to ideas in a story, all important cognitive multi-tasking strategies essential for reading. Albeit, the goal of reading is to figure out implicit links in multi layered texts, translating the abstract and complex messages in to understandable terms. Nevertheless, it takes explicit scaffolding by a skilled teacher including demonstrations and multimodal strategies [10] such as visuals, drawings, storyboards, talk-drawings, diagrams, charts, concept maps, and digital representations throughout a reading task. Visual Images are a monitor of comprehension. When students with a FASD diagnosis are taught to generate mental images while reading, their recall increases and so does their ability to predict a text and makes inferences about what that are reading. Using Talk-Drawings are an illustration of what the texted stated and makes the meaning of the words more memorable [11]. Visuals provide a visible and explicit record of learning [12], as struggling readers may lack the memory "pegs" for specific details within a text. Visual representations bridge the memory pegs to connect with appropriate background knowledge before, while and after reading.
Drawing has the potential to play a mediating role in the visualization of ideas and concepts in relation to young children exploring every-day stories or scientific concepts. This research explores how drawing and visualization bridges the gap between perception-bound thinking and more abstract, symbolical thinking. It demonstrates how drawing, and the related visualization that results from drawing. These pedagogies are congruent with the language experience approach to reading, which taps children's own language, culture and prior experiences ensuring familiarity with the content and vocabulary of the drawing, oral storytelling, reading, and writing activities. The more that readers with FASD are able to orally elaborate or represent their own ideas through images, the more concrete the story world becomes for them and the more relevant the engagement and cognitive multi-tasking strategies essential for reading.

\section{Results}

(1) Visual mediational strategies used within the interactive dynamic assessment study were closely related to successful academic and social learning processes in school and to other life contexts. (2) The qualitative measuring of diagnostic and formative information for higher order thinking skills, and deficient cognitive functions that are responsible for literacy learning difficulties were implemented. If children with FASD are not learning the way we teach, then we need to teach the way they learn. In this study, introducing visual strategies that facilitate learning through reading or writing tasks were effective in providing "an explicit record of learning" as readers and writers with FASD used visual memory pegs for specific functions within literacy tasks.

\section{Competing Interests}

The author declare that there is no competing interests regarding the publication of this article.

\section{References}

1. Streissguth AP (2006) Fetal Alcohol Syndrome: A Guide for Families. Toronto: Paul H. Brokers Publishing Co.

2. Edmonds K, Crichton S (2008) Analyzing narrative productions in older school-age children and adolescents with Fetal Alcohol Syndrome: an experimental tool for clinical applications. Clinical Linguistics and Phonetics 12: $221-236$.

3. Vygotsky LS (1986) Thought and language. Rev ed Cambridge, MA: MIT.

4. Lesley M, Labbo L (2003) A pedagogy of control: Worksheets and the Special needs child. Language Arts 80: 444-452.

5. Feuerstein G (2008) The Yoga Tradition: Its History, Literature, Philosophy, and Practice.

6. Tzuriel D (2000) Dynamic Assessment of Young Children: Educational and Intervention Perspectives. Educational Psychology Review 12: 385-435.

7. Wason-Ellam L (2012) When Comprehension Fails: Making Reading Repairs. Query.

8. Tierney RJ, Cunningham JW (1984) Teaching reading comprehension. In PD Pearson (Ed.), Handbook of Research in Reading. New York: Longman.

9. Pressley $M$ (2000) What Should Comprehension Instruction Be the Instruction of? In: M. Kamil, P. Mosenthal, P. Pearson, \& R. Barr (Eds.) Handbook of Reading Research (Vol. III, pp. 545-561). Mahwah, NJ: Lawrence Erlbaum.

10. Kress WJ, Wurdack KJ, Zimmer EA, Weigt LA, Janzen DH (2005) Use of DNA barcodes to identify flowering plants. PNAS 102: 8369-8374.

11. Wright $S$ (2005) Children's multimodal meaning-making through drawing and storytelling. Teachers College Record.

12. Hibbing, Rankin-Erickson (2003) A picture is worth a thousand words, using visual images to improve comprehension. The Reading teacher 56: 758-770. 